\title{
Practices, Processes, and Systems Design: Why Consultants Need to be "Everyday Ethnographers"
}

\author{
Gary C. David* \\ Associate Professor of Sociology, Department of Sociology, Bentley University \\ Address: 175 Forest str., Waltham, Massachusetts, USA 02452 \\ E-mail: gdavid@bentley.edu
}

\author{
Susan Newell \\ Professor of Information Systems, Department of Business and Management, University of Sussex \\ Address: Sussex House, Falmer Brighton, United Kingdom BN1 9 RH \\ E-mail: sue.newell@sussex.ac.uk
}

\begin{abstract}
Enterprise systems (ES) are intended to tie together the various functions of an organization through the integration of information flows, data management, organizational processes, and workplace activities. Compared to legacy systems, which can be siloed in disparate parts of the organization, enterprise systems are meant to be used across the entire 'enterprise'. The biggest benefits of these systems include businesses achieving greater standardization of work, data management, and having an information system that makes for better decision making and greater responsiveness to changing conditions. As they constitute a fundamental shift in how work is done, ES can be inherently disruptive as the technological landscape of an organization is transformed through the installation of a new information system. This also makes them prone to failure, as the installation of the system is often met with large delays, user resistance, and a failure to integrate with existing work practices. In this paper, we contrast reengineering approaches (i.e. the restructure of work) with implementations in which the technology is fitted more to existing work practices, to achieve more incremental and less disruptive change. We argue that while consultants strongly promote a reengineering-led ES implementation, their adopted methodology for understanding existing business processes is such that they are able to grasp only an idealized view of these processes, often very different from actual practice in any specific context. We propose instead that consultants adopt a practice-based, ethno-methodological approach, essentially becoming everyday ethnographers, who can better inform these business, organizational, and managerial decisions.
\end{abstract}

Keywords: information systems, workplace studies, ethnomethodology, enterprise systems, re-engineering, consultants, business processes

(c) Gary C. David, 2016

(C) Susan Newell, 2016

(C) Centre for Fundamental Sociology, 2016

* Please direct all correspondence to Gary David.

DOI: $10.17323 / 1728-192 \mathrm{X}-2016-1-9-33$ 


\section{Introduction}

Enterprise systems are technological solutions designed to create an integrated work infrastructure so that an organization's information and "knowledge" is readily available to its employees. Much has been written about the disruption and expense of introducing ES, and about the failure of such systems to live up to their billing in terms of increased savings and productivity, and sometimes even about their complete failure and abandonment. A less developed area of investigation centers on the extent to which ES actually support, or in fact interfere with, activities in the workplace. We focus on this issue in this paper. We develop an analysis of this interference through exploring different rationales for ES implementations: (1) upgrading independent legacy systems in order to better support existing workplace practices; or (2) using a new technological system to fundamentally transform (or reengineer) the organizational processes. If an organization has the first goal, technology is seen as facilitating work by providing better tools to employees. Under the second rationale, technology is seen as structuring work by providing a framework through which work gets done.

As we discuss, those involved in ES implementation may conflict over which of these two goals is most appropriate. Here we focus on the difference between consultants brought in to support an ES implementation, and those from the client firm involved in the implementation. Due to their knowledge of the system and prior experience, consultants are frequently in a position to influence the goals of the organization. As we demonstrate, consultants often use this power to promote goals related to organizational transformation and restructuring rather than to facilitate and enable existing work practices. In promoting this goal, consultants are advocating ES implementation process that includes a major reengineering of the business processes. On the other hand, as we also demonstrate, companies are often hesitant to disrupt their current workplace activities, opting for an upgrade in functionality to support workplace practice rather than a radical restructuring. The consultant's view is often assumed to be the legitimate view. However, in this paper we question the consultant's view, exploring how their process-based view of an ES is based on an idealized version of how work is done (process) which is very different to how work is accomplished as an on-going, everyday practical achievement (practice).

In this paper, then, we critically explore the role of consultants in supporting ES implementations. We argue that their focus in the design of an ES on how processes should be undertaken, rather than on how work is actually carried out in practice, at least in part explains why many ES fail to live up to their expectations. Furthermore, this paper explores the roots of the divergence between how ES are designed and implemented, and workplace practices. We argue that while consultants strongly promote a reengineeringled ES implementation, their adopted methodology for understanding existing business processes is such that they are able to grasp only an idealized view of these processes, often very different from actual practice in any specific context. We propose instead that consultants adopt a practice-based, ethno-methodological approach, essentially becom- 
ing everyday ethnographers, who can better inform these business, organizational, and managerial decisions.

\section{Consultant and Client Power Relations}

In the course of designing and implementing ES, clients and consultants often need to work together and negotiate what the final system will look like. As with all negotiations, the negotiating partners may begin far apart in terms of their respective visions of what the final outcome should be. The negotiation process also can be impacted by the power and resources that each side brings to the table. Unequal power typically leads to unequal outcomes in terms of one side being able to achieve more of what they want than the other. In terms of the client and consultant relationship, where power actually lies can be counterintuitive. One may assume that since the client is in fact the "customer" paying for the consultant's services, the client has ultimate power. However, research on the relationship has shown that, for a variety of reasons, the consultants can hold more power in the relationship and, in essence, design the system.

The main reason for consultant power in this relationship is the critical role of the consultant in the implementation of ES. As Steve Bender, a supply side chain manager for Toshiba, observes, "You can have the best package in the world, but if you can't get it implemented, it won't do you much good" (Michel, 1998: 44). Since consultants are (ideally) experienced with the package being implemented, they are vital in helping a company to get the system running and people using it. However, their role is not limited to technological expertise in terms of the functionality of the system. A fundamental, and not completely understood, aspect of consultant work is the way in which consultants are able to construct the nature of "problems" or "challenges" present in the organizations, and how the system will "solve" these problems. In other words, the technological expertise of consultants allows them to manage and administer more than just the technology itself. It allows them to construct, manage and administer the setting itself.

In order for a consultant to be seen as reliable and knowledgeable, the consultant needs to convey competence and expertise. Accordingly, drawing from the work of sociologist Erving Goffman (1959), Clark and Salaman (1998: 18) assert that the most important part of the consultant's job is "impression management":

[T] he art of impression management (i.e., the manipulation and regulation of images relating to client perceptions of the service delivered) is at the core of consultancy work. Indeed the rationale for management consultants existing and their economic success are dependent upon the extent to which they can make credible (i.e., project) to clients their claim to offer something special, i.e., a high-quality service which can be valued.

According to Clark and Salaman much of the power inherent in a consultant's work does not derive from their knowledge and expertise per se, but also from their ability to convey that they have knowledge and expertise. Thus, consultants must behave like consultants, 
and in doing so create a situation where they are believable as consultants. By being "believable," consultants are also able to construct what is seen as a legitimate representation of the workplace, the problems and issues that the organization is facing, and the ways in which technological systems can address those problems and issues. In other words, "style" can be more important than "substance" at least initially in the relationship (Alvesson, 2001).

Jones (2003: 282) observes that consultant expertise "may be seen as created in the interaction of client and consultant, drawing on a system of elements, including technical knowledge, skilled practice, individual and collective experience, and commercial interests." The work of consultants, like all work, is a social achievement, enacted in and through their encounters and interactions in the workplace. Consultants, often positioned between vendors and clients, are in an influential position to mediate the system and its requirements to the client, with the potential to create the system and its implementation in their own image (see Haines, Goodhue, 2003). In this way, the consultant as "outsider" can dictate to "insiders" what they should do.

In their examination of how IT consultants can exercise power in the course of their work, Bloomfield and Best (1992: 542) assert that it is necessary for "IT consultants to represent or stand-in for technology (both hardware and software), to say what is and isn't technically possible and thus, implicitly, what is technical and what is social." Their power comes from the knowledge differential between the consultant and the client. The consultant is paid for his or her expertise, and is expected to know more than the client. By virtue of being the "knower," the consultant is already in a position to tell the client what needs to be done and how to do it. The client, on the other hand, is beholden in this relationship to the consultant to lead the way.

Bloomfield and Best's study is based on Callon's (1986) and Latour's (1987) sociology of translation, which examines how one agent is able to translate his or her own interest to another agent, and thereby convince the other agent to follow a course of action. Upon entering an organizational setting, consultants are in a position to assess and recommend based on their judgment as experts. The final step in translation is to convince the client that the recommended course of action is the best course of action, and that it in the best interests of the organization.

Consultants can be seen as cognizant of the necessity to manage their image in such a way as to convey authority and knowledge. Likewise, clients are aware of their position as clients in need of assistance. Thus, each has a role in the relationship: one to advise and one to consent. The question can then be asked, "what is the origin of the advice?" More specifically, is the advice given by consultants based on what they have observed in the organizational setting itself, or is it based on their concept of what organizations should ultimately look like? Put differently, are designs and implementations being done to augment existing workplace practices or to completely reconfigure (or reengineer) them with no regard to what currently exists? This is a critical question, as the answer could have a tremendous impact on the level to which systems are adopted and used by workers, ultimately contributing to productivity, satisfaction, and recouping the original 
expenditure to implement the system. We consider this question next by exploring the distinction between work processes and work practices.

\section{Business Processes and Workplace Practices}

Business processes and workplace practices are two concepts that frequently are treated synonymously. Typically, these terms are used to describe what occurs in the workplace regarding how work is accomplished. There are, however, critical differences between the two, especially when developing ES meant to integrate the workplace. Process refers to a generalized sense of how work gets done in an organization based upon rules, methodologies, standardized protocols, or other sets of explicit instructions meant to provide structure regarding how people should do their jobs. Practice, on the other hand, refers to the ways in which work is actually accomplished on a daily basis as an on-going emergent accomplishment. Both obviously are important to accomplishing organizational goals, whatever those goals might be. Furthermore, by raising this distinction between process and practice, we do not mean to assert that one is more important than the other. Rather, by making this distinction we want to draw attention to the roles that process and practice play not only in how work is done, but how both need to be understood in order to develop work-based technological systems.

For the most part, consultants focus on processes rather than practices-idealized models of how work "should" be done to optimize efficiency (Ciborra and associates, 2000). This is epitomized in the "best practice" ES industry models which are essentially idealized models of fulfilling each business process in any given industry. Systems are built with an emphasis on process, with the "best" processes derived from an "objective" reengineering effort (Hammer, Champy, 1993) which ignores all current practices, starting with a blank sheet to determine optimal processes for a whole industry. Rules and methodologies become enshrined in these systems and workers become accountable to them. Whether described as processes, models, plans, protocols, "best practices" or methodologies, collectively these terms stand for a set of standardized and generalizable approaches within an organization that are codified and explicitly stated (Dant, Francis, 1998).

Plans and processes are the broad strokes or general parameters within which organizational activities are expected to take place. For workers, they provide a referent to their place in the organization and awareness of the workflows and expectations not only of themselves but of all others in the organization as well. For managers, plans and processes provide a view of organizational activity and a framework by which progress and success can be judged. Overall, plans and processes can be used as an orientation tool or roadmap to guide persons and situate the organization (Lynch, 2002).

The problem is that the models and frameworks used by consultants to design work processes in an ES implementation are not based on any direct observation of work practices but rather involve a respecification of ordinary activities into generalized categories and theoretical frameworks based on an idealized view of the world. This serves 
to obscure the practices that are the foundation of social order. Ciborra and associates (2000: 27) note that researchers who focus only on the abstract concepts in a model "remain blind to the blurred reality of connections that any, even "light" ethnographic study would present them." In order to understand the nature of the social order in any localized setting, it is imperative to witness the activities that make the setting possible and recognizable as such. Ciborra refers to this as the superstructure- "the lifeworld and the immediate evidence of our lived experience" (Ciborra and associates, 2000: 28).

This means that in order to understand how work gets done, attention needs to be directed to everyday mundane activities in the workplace (or workplace practices). Even though workplace practices are important to any study of work, they have not received much attention (Sharrock, Anderson, 1986). While work as a topic has been studied, work as a practice has not. This is true both in the academic literature and in consulting practice. This means that consultants pay little attention to the actual ways in which work is done as a practical, everyday embodied achievement. Barley (1996: xi) goes so far as to say that "work has become invisible." In its place are descriptions, surveys, or narratives regarding what work is thought to be. Even those engaged in work may be unable to explicitly describe the detail of their tasks. Part of this is due to the fact that much of our work, in its repetitive nature, approaches the level of the mundane, taken-for-granted, and for those who perform the work, generally uninteresting. As a result, any description is potentially lacking.

If it is difficult for workers to describe what it is they do, then managers face an even greater challenge. Managers may be well versed in organizational processes, and their reliance on plans and processes reflects a preoccupation with trying to develop rational systems of operation in the workplace (Dant, Francis, 1998) that they can control (Ciborra, 1996). Processes create a series of steps that can be controlled and monitored and against which people can be held accountable, creating a sense of managed predictability. However, despite a thorough knowledge of processes, managers are not necessarily in touch with workplace practices (Colclough, Tolbert, 1992). Furthermore, since managers are more knowledgeable of processes, they often rely on them as complete accounts of work. "[Abstract characterizations of ordering structures of work] are not necessarily wrong but fail to appreciate, take for granted, and in other ways ignore the real world, real time ways in which an organization's staff comes to comply with rules and procedures" (Crabtree, 2001: 9). Thus, relying on narrative descriptions of workplace practices, be it from managers, workers, or consultants, does not provide an adequate understanding of the embodied coordinated action of workers in the workplace. A focus on actual practice, demonstrates that the plans for an information system implementation, for example, often do not match the reality. Ciborra (1996) refers to this as "technology drifting."

This shows the potential problems inherent in building technological systems based solely (or primarily) on organizational processes. More specifically, as a result of practices (or how work gets done on a daily basis) being superseded by processes, workplace practices are disrupted and systems meant to improve work can have the opposite effect. Brown and Duguid (2002: 69) summarize this point: 
First, many of the difficulties reflect a misunderstanding of office work, which is too easily painted as information handling... Second, bold predictions about the spread of hot desking and electronic cottages may also ignore the frailty of technological systems. ... And third, by overlooking both the social aspects of work and the frailty of technology, a design that attempts to replace conventional work systems may often merely displace the burdens of work.

In general, technological systems can be "frail" in terms of being able to support the social aspects of work that occur on a daily basis, and in essence form the information and knowledge backbone of the organization. The fact that the social aspects of work and the limitations of technological systems are ignored in the design of information systems leads to systems that are themselves limited and counterproductive (Orlikowski, 1991).

The way in which process-based systems, like ES, can disrupt work practice is rooted in worker accountability to these systems. "Accountability means just that we hold each other responsible for the intelligibility of our actions in relation to the circumstances at hand" (Suchman, Trigg, Blomberg 2002: 164). Because mutual intelligibility and the foundation of social order rests on the ability of people to meet the jointly shared expectations regarding what people "do" in a setting, people need to be held accountable for any digression or failure to meet these expectations. In such an event, people have to "account for" their behavior in terms of why they failed to enact the appropriate processes (Koskinen, 2000a). In other words, processes and the associated procedures and plans specified by managers are often seen as the accountability structures for workers, to which they must conform. Of course, it is not that managers are in a position to actively monitor the minutiae of workers' daily activities. Managers traditionally have had to rely on reports to gauge the extent to which workers are following the workplace protocols and procedures. It is then important for workers to be able to produce reports and records that demonstrated their following of the protocols and processes of the workplace, regardless of whether the protocols are in fact explicitly followed.

In fact, research on workplace practice has shown that rather than following explicit processes, workers often accomplish their tasks via routes that have emerged from the setting in which they occur. Koskinen (20oob: 7) also observes, "Even in highly standardized environments, people surprise." He adds, "People are not 'cultural dopes, run by drives, structures or meanings from behind their back; rather, they are reasoning, watchful creatures who are doing their tasks in contexts of their own creation" (p. 4). This means that the practices used by workers to accomplish their work can diverge from the processes of the workplace. While workers are accountable to the processes, they are accountable to the production of structures that recognizably show they are following "the rules." This leaves room for workers to use ad hoc ways of actually accomplishing their tasks that may be outside of the protocols, processes, and procedures (Orlikowski, 1996).

A potential problem emerges when workers are held accountable to technological systems in terms of how they do their work, or more specifically whether they follow the organizational protocols. Technologically-based accountability creates a higher-order 
level of organizational accountability. The system cannot be negotiated with, and does not recognize abstract situational contingencies that often arise in the workplace. Workers are then expected to follow a restrictive algorithm in which they cannot use ad hoc practices to successfully accomplish their tasks. This means that in order to have systems that compliment rather than impede work, it is vital to design systems that are built in some respect around workplace practices, and to recognize how processes and practices figure into organizational activity.

The issues raised in the preceding sections suggest that there are a number of possible options and outcomes in the planning, design, and implementation of a workplace technological system. In particular, there is the option of whether the project will involve the implementation of a model-based (or "best practice") system versus something built around the situated context of practices in the targeted workplace. In other words, what choices are made about the level of configurability and customization of the system? There is also the question of whether there are differences between stakeholder groups (in particular between consultants and firm representatives involved in the implementation) in terms of these preferences; is the system meant to be part of a reengineering process or is it meant to support and improve existing organizational activities without substantial transformation? The decisions made regarding these options will have a tremendous impact on the final product and its effect on the workplace. We explore these questions using empirical data collected from a variety of sources.

\section{Methodology}

We explore the topic of this paper through two case studies. In the first case study, we investigated the experiences of ES consultants $(\mathrm{N}=10)$ who work in a large consultancy firm (hereafter called XYZ). Each consultant had been involved in many external ES implementations. We decided to consider this broader experience of consultants because consultants have wide-ranging involvement in a variety of companies which are likely to approach their ES adoptions very differently. We would have to conduct many case studies in different organizations to gain access to the type of diversity in ES implementations that we were looking for. As this was an exploratory study, a series of open-ended questions were asked of each consultant, which was then followed by less systematic probing questions. This provided a corpus of rich, qualitative data rather than quantitative data, which could have been collected by a survey instrument. In addition to these interviews we collected documents related to XYZ's implementation methodology. The purpose of collecting data from multiple sources was to enrich the depth of the study, and to triangulate the data to ensure the validity and reliability of the findings (Denzin, 1989).

To get a sense of the implementation from a client's perspective, we also examined a small distributor of office furniture, which was in the process of implementing an ES system. The company (hereafter called Furniture Co.) has 320 employees distributed throughout 7 sites in New England. While Furniture Co. is small, it is serves as a distributor for a major furniture company who had over $\$ 2$ billion in sales in 2001, with locations 
around the globe. While existing as a separate entity, it is closely intertwined with the business process of the major manufacturer. Our study of Furniture Co. involved discussions with the $\mathrm{CIO}$ and other managers $(\mathrm{N}=3)$ principally involved in the system implementation. The study of Furniture Co., in its initial stages, involved conversations with the team $(\mathrm{N}=5)$ charged with the company's readiness assessment and compiling an inventory of workplace practices, as well as the examination of documents associated with the overall process, from planning to implementation. This case was interpretative in the sense that the aim was to produce "an understanding of the context of the information systems, and the process whereby the information system influences and is influenced by its context" (Walsham, 1993: 4-5).

\section{Competing Client and Consultant Perspectives}

The central points that we wish to illustrate with our consultant empirical data are that consultants believe that ES implementations should be used as opportunities for radically reengineering business processes, despite the fact that their clients often oppose this; and that the reengineering that they propose is not based on any study of actual work practice. We use supplementary data from the Furniture Co. case to illustrate the same points but from the perspective of the client rather than the consultant. The Furniture Co. case provides a practical illustration of why consultants' claim that reengineering is always necessary is over-stated. In this case, Furniture Co. dismissed the claim of the consultants that an ES represented "best practice." They realized that implementing the ES that their key customer wanted them to, would mean that they would have to radically reengineer their processes, and they believed that this would impede workplace practices and hurt productivity (as well as morale). They opted instead to work with a different vendor to develop a tool to support their existing work practice; this was very successful, although not without its own headaches.

\section{Case One: Consultant Vision and Reengnineering as Priority}

Among the consultants interviewed, there was general agreement that some degree of reengineering is essential in an ES implementation in order to achieve the transformational potential. There was the sense that part of being a good consultant is emphasizing the reengineering aspect of an implementation. Technology is seen as both the opportunity for and the vehicle of this transformation.

That's the intent [to get them to reengineer upfront]. To fully utilize the SAP functionality, which is a totally integrated system. To fully utilize the functionality of SAP. And often part of using that means making changes as you know which is why we strongly recommend to try and help facilitate making those changes.

(XYZ consultant) 
We see here that to get the most out of the system, the consultant emphasizes that a company must enter on a course to reengineer their business processes. The implication is that which defines a "successful" implementation is not just whether the system is functional, but that the end result is a transformation of the organization's processes. The larger goal for the consultant is to initiate and bring about a total transformation. Most of the consultants we interviewed made similar comments. Their rationale was that, given the high costs of ES implementations, they need to promote at least some level of transformation to support the expenditures and the time necessary for the implementation.

Improved functionality goes beyond the user experience and use. In fact, user experience is only measured in terms of the extent to which the technology leads the user to follow a certain process. This is made clear by the extent to which costs meant for "people issues" are cut in lieu of increased expenditures for "IT issues," as indicated in this interview with a consultant:

Second Interviewer: $\mathrm{Xxxx}$, if I were to summarize what you said, briefly, it sounds to me like there are a whole lot of people issues, but that the IT issues continually take precedence over those people issues.

Respondent: Yes, because they are more urgent. You can solve the people issues as you go, or theoretically as you go, but you can't solve the IT issues as you go. You need to solve them right now because they stop us.

"People issues", such as training, frequently are seen as things that can solve themselves through people's exposure and repeated use of the system. This is not to say that training is not seen as important or vital to success. The point is that technological (or more specifically IT issues) are given prominence in terms of how resources should be distributed. It is interesting to see that IT issues are seen as something that can stop a project, while people issues are not. This means that a project can meet its IT benchmarks and be seen to be on track, while "people benchmarks" can be lagging.

Resistance from users and management to the consultant's plans is the greatest obstacle in their work. A lot of their time may be devoted to convincing both groups of their vision. It therefore is interesting to hear from consultants that employees that are newer to the organization (and often younger) are easier to work with because they are not invested in the pre-existing legacy systems:

Second Interviewer: Do you find it generally easier if people don't have an idea and you can train them versus having some idea that's mistaken ...

Respondent (JM): Well, you know, it's interesting you ask that because one of the easiest implementations we had was with one company. And understand the profile of the customer in the company is critical in terms of going in and preparing. And one of the things we found was, we were very very nervous initially because the profile of the people who were going live with SAP was about a year or two experience out of school. No SAP experience. And we were really concerned about it. The more we thought about it, the more we put the plan together, we realized this 
is going to be the easiest implementation we've ever done. They don't go in there with any predetermined way they want to do it. They found it exciting. The thought that they were actually learning something called SAP . . . it was one of the easiest implementations because they had no knowledge of SAP and very little business experience. Now there were other challenges associated with that but that was one of the easiest ones.

This speaks to the degree to which consultants can "guide" a client through the implementation process according to the vision of the consultant. Workers who have already developed a sense of how their work is done, and how tools should function in pursuit of accomplishing that work, generally are more resistant to "outsiders" coming in and dictating the implementation of new technology. Employees who are not vested in welldeveloped localized workplace practices are more amenable to the introduction of new ways of doing work. In a sense, newer (and younger) workers do not know any better than what the consultant is presenting. This provides the consultant with leverage to implement "best practice" technology that may not match local practice.

One consultant interviewed termed the desire to continue to do things the way they have been done as "legacy thinking":

But I think actually most of that was really to do with legacy thinking. You know, thinking in the way in which they were doing the work before and not really being able to see how this should be working in the future. Because the reality is that once we've deployed the system the problems that they thought they might have were nothing like the problems they actually got. And in many ways I think the exploitation of the system is yet to be fulfilled. So the system's starting to get there but there's no [trick to] getting there from a really truly planned exploitation and that's sort of the current.

(Respondent DH)

This consultant demonstrates user hesitancy around implementations because of the fear of massive disruption to how they currently work. While ES often promises more streamlined performance and greater productivity, as the consultant comments, "the problems that they thought they might have were nothing like the problems that they actually got." Much like any other tool, to be productive it must be integrated into the workplace on the terms of those who are going to use it. As a result, massive broad-based changes to the workplace environment will undoubtedly cause some (perhaps massive) disruption. In a fast-paced business environment in which experienced workers have developed their own unique sets of tacit knowledge and practical work-arounds, any disruption can be highly troublesome. However, as we have already seen, the "soft" issues of training and gaining user commitment to ES are often seen to be less important than the "hard" technical issue of getting a functioning IT system.

The extent to which consultants are not willing to entertain worker (and management) inputs is clear in descriptions of how consultants initially engage organization personnel in discussing with them the system to be implemented. Consultants relate that the 
first step is to examine how things function "as-is." This is done in a variety of ways, but predominantly through an examination of the current existing process as laid out in organizational methodologies. This is compared to what is "to-be," or what the system once implemented will look like. The "gap" between the two is then examined in terms of what the transition is to be. The extensive illustration below from one consultant demonstrates this:

Respondent (PM): We kicked off in Jan 2000 and with a session called "fit-gap." We brought together a representative sample from around the world into a large conference room and we walked them through screen by screen the application and we challenged them to accept it "as is," out of the box. There was a lot of discussion during the week long meeting. At the end we had fundamentally work-flowed how these people did their job. As an aside, there is an interesting difference between the process documents, how they say the job is done, and the people at the keyboard actually doing the job. They don't match. You get very clever people who learn their own short-cuts and unless you are a practitioner you don't learn these things. At the end of the week we had identified the differences between the way they wanted to do their job and how the tool enabled them to do their job. They came out with six hundred-plus requirements for customization and in the first release which we launched in April 2000 we enabled eight customizations and we said we were not doing the rest of these six hundred. The rationale was to keep as close to out-of-thebox as possible. We were really striving to minimize the number of customizations that had to be made to the application. The process by itself ought to survive any application, and it is really a matter of different work habits. For example, if, in the legacy system, a person could type the address on the same page as the name was typed, the new tool might not support this but it does not affect the process. A person ought to be able to adapt to these minor modifications. The things that we did accept were, for example, if the application said "client name" and we use "customer name." Those were the adaptations we made just to be able to smooth the nomenclature and terminology. Was this accepted? Grudgingly. The executives accepted it much more readily than the users do. We tolerate a fair amount of complaints (laughs).

There is much in this comment that speaks to the larger point of this paper. First, personnel are brought in from all over the world basically to accept the program "as-is" or "outof-the-box." "Vanilla" implementations generally are encouraged by consultants because of their belief that the ES system truly represents a "best practice" model of how work should be done in an organization. By pushing the system as it is, the consultants are also pushing the best practice model that the system is built on. This gets back to the belief that ES systems are not simply technical tools but transformational ones.

A second important point in this quote is the realization that the processes of an organization do not necessarily match the practices of the employees. However, it is interesting how these divergences are treated. As the consultant relates, the workers who were brought in from all over the world recommended over six hundred customizations to the system. In the end, only eight recommendations were enabled. Modifications that were 
made were nominal. As the consultant stated, "We were really striving to minimize the number of customizations that had to be made to the application. The process by itself ought to survive any application, and it is really a matter of different work habits." The "different work habits" are clearly minimized in lieu of "the process by itself." This gets to the crux of the matter: legacy systems generally are more flexible in terms of how workers can adapt them to suit their own local workplace practices. ES, on the other hand, are not. When flexibility is lost in the technical system, it is expected to be taken up by the workers in terms of adapting to the new system.

The theme of "no customization" was widely shared by the consultants interviewed, as was the expectation that workers need to adapt their practices to the technology, rather than the technology to the practice. The following comments by another consultant show how consultants actively work at convincing organizations and workers to adopt the standard system:

First Interviewer: Now in doing that does that mean that they take the (standard) system and then they configure it to suit the processes as they almost exist currently in their organization?

Respondent (JM): They try to do that. But if we're doing our job as consultants we try very hard to not let that happen because I'm sure if you've worked with SAP, SAP 101, the first thing you say to a customer or client if they know nothing about SAP, (which is almost everyone when we start) was: you do not change SAP to meet your requirements and your processes. You don't do that. SAP is going to help you by going in and looking at your processes and we are going to reengineer your processes for you. You are not going to change SAP. And that's, as you know, that's typically the approach.

Clearly, "our job as consultants" is to minimize any attempt at modification of the standard system. The consultant goes so far as to say, "You do not change SAP to meet your requirements and your processes. ... SAP is going to help you by going in and look at your processes and we are going to reengineer your processes for you."

From this it is clear that while reengineering is a high priority among consultants, it is not a high priority among companies, many of whom attempt to avoid reengineering as much as possible. This tension is demonstrated in the following two consultant comments:

I mentioned earlier a lot of times reengineering and best practices are not always the focal point. They really are not. As much as we would like them to be and we try to drive that, a lot of the time they're not. So they'll look at what standard SAP provides. They'll look at what they have today. And try to go through as little change as possible and that's the way I can describe it. And we, as consultants and as advisors, our challenge is to get them to understand that the answer is not as little change as possible. The answer is take advantage of the opportunity to improve what you have, to reengineer if that's what you're invested in. Quite frankly that's not always the case. Human nature-as you know probably better than I do-doesn't want to 
change. They say, I want to stay with what I have and what's the least painful way that I can do this (emphasis added).

In ES implementations the word reengineering is sometimes overused. Because quite often with all good intentions and all good advice from very good consultants, companies typically reject the time and all the dynamics associated with a major reengineering effort. What they say instead is here's what I have today. I know you're asking me, I know my company wants you to do this SAP implementation. I want to go through with as the minimal amount of change as I can. I don't want to do any reengineering if I don't have to. And just make sure you give me what I have today only you think you can do it better with SAP. That's more often than not the way these evolve (emphasis added).

Despite the best efforts of the consultant at reengineering, and the potential backing of high-level management, workers themselves are often hesitant to reengineer.

The hesitancy to reengineer was prominent with managers at Furniture Co. Furniture Co.s primary supplier was implementing a system that was meant to transform the company's sites (as well as distributors' like Furniture Co.) into an integrated network. This would mean that Furniture Co. would have to radically alter their processes to fit the new systems design offered by the supplier. However, the major sentiment at Furniture Co. was that they did not want the system to impose this level of change on the organization. While they recognized the need for a new system, the primary aim for this system was to increase the functionality offered by the current legacy system, and through this new system gain efficiency and cut costs. Some organizational transformation was expected; but the pace of change was to be incremental.

Rather than having the technology drive the business process; they wanted the business process to drive the technology. This put Furniture Co. in a situation of going out on their own to develop their own system from another vendor. They did this so they could have more control over the project and the final outcome, which was intended to support the practices they already had in place. In the course of selecting their own vendor, they were able to weigh their desires for incremental change and limited reengineering. This would be a greater challenge than originally thought.

\section{A Practice-based Approach to Systems Design}

Furniture Co. chose a small-scale vendor that wanted to use Furniture Co.s system as an avenue to break into the furniture distributor market. Furthermore, since Furniture Co. is well-known in the world of office furniture, their recommendation regarding satisfaction would go a long way in helping the vendor establish themselves. This meant that the vendor was in a position to please the client, giving the client a good measure of control over the relationship. This is an important difference in other client/vendor relationships where the vendor usually holds the majority of the control. Since control was held by the client, this affected the dynamics of the relationship, and allowed the client to exercise more authority. 
As part of their engagement with the vendor, Furniture Co. embarked on a readiness assessment where they documented all workplace activities, including reports generated, databases used, technological systems, and any other artifacts of the environment. The readiness assessment team was composed of five employees whose job it was to understand all workplace practices. A site was established at the distribution warehouse for the team to map the workplace practices and business processes. A final report was produced with all of this information which was to be used as the basis for the systems design. The management of Furniture Co. assumed change would emerge from their better understanding of their own workplace practices and the implementation of this new system.

Despite the proactive efforts of Furniture Co., major problems emerged with the vendor who, rather than build a system to their specifications, built a system around an idealized sense of what their processes should be rather than what the practices actually were. The consultant, acting on behalf of the vendor, attempted (in the words of the management team) to "ram" the system into the organization. However, the consultant did not have an adequate understanding of the company or the company's work. This was a constant theme in discussions with Furniture Co. personnel, as seen in the comments of one of Furniture Co.s top managers:

[W]e had spent 15 years developing something that is successful to become the number one dealer in this industry, we must have done something right. Give us credit for doing something right, and they come in [and] you have to place orders a certain way, so we have to change the way we do business and it will cost us to do that. Then where is the benefit in a small business to do that?

For this manager, it makes no sense to have consultants come in and dictate how they should do their work, especially given how successful they have been in building their business over the last 15 years. Furthermore, he acknowledges that a shift from how the organization does its work "will cost us." While Furniture Co. could see the immediate benefits of better functionality, there was no desire to have consultants, or the system, dictate the specifics of how their work should be done.

A common refrain among the consultants interviewed was that workers frequently are resistant to change in terms of the impact that the ES systems will have on their job. In our conversations with the lead consultant at Furniture Co., he made the same point except his comments were directed at the consultants in his own company. As he states here, many people at his company are similarly resistance to change their product to suit the client:

Interviewer: When you think that your way is the best, then you really have to learn their culture to appreciate that, there is a difference and that difference is important. What they do and how they do it is important and you have to judge what they do and learn it.

Consultant: We have a lot of people at (our vendor company) that think, well this is the way it works and this is the way that you have to use it and we always have argu- 
ments about that because we could make it better. Just because this is the way it was in the past and is [now], doesn't mean that it has to carry on that way. Sometimes people don't want to make change unfortunately.

The last sentiments of "Sometimes people don't want to make change unfortunately" are very similar to what consultants have said about workers and management. In this instance, however, the consultant notes that the resistance to change in his own company meant that the project with Furniture Co. was being delayed and becoming increasingly problematic. The people at the vendor company believe that the standard system being offered should suffice to support the operations at Furniture Co.

Interestingly, the lead consultant with Furniture Co. was originally of the same opinion in terms of believing the standard system represented "best practices" that should be adopted by Furniture Co. However, in the course of the interview with him, he made this comment regarding "learning the business":

Interviewer: One of the things that you mentioned when you were learning about the furniture industry, is how steep has your learning curve been since you have been involved in this project. How well do you know how the intricacies of the furniture industry work?

Consultant: When I first came onto this project, my main focus had always been the supply side and I was forced to learn the furniture side, I didn't really know much about the furniture side of the business. But Xxx knew and since working with him, I have learned quite a bit. I think that was good because before that I was prejudiced; saying "well, this is how I know this needs to be and this is how you need to do it." I could see where our system was hindering them in certain areas; that we needed to make changes so that they could use it more efficiently.

The consultant comments on his new-found ability to take the perspective of Furniture Co. in terms of viewing the system and its limitations. It is interesting to hear him frame his former mindset as "prejudiced." We see here the transformation of power relations from the consultant dictating how a system is going to be, to the consultant partnering with the client in terms of working out the specifics of the system.

Thus, client and vendor are able to more cooperatively achieve a negotiated design. It needs to be noted that the person interviewed was not the original consultant involved in the project. The original consultant was dismissed by Furniture Co. because of his inability to work with the company's management, and the problems that ensued with the original roll-out of the vendor system, as illustrated by the comments of the CIO:

It is a partnership. When I got into this, we went in as a partnership. What really bothered me, and I took it to heart, was when they started nickel and diming for tiny things, like you didn't specify or use, with an X. I said give me a break. I didn't know your software had multiple places that you could access that information. Well, are we going to want that? And I said that is not fair. I could never know what I know today. We would still be negotiating the contract and I don't think we would 
want to be in that position because it would never have gotten signed, so let's work together on this. And I had to concede. I had to concede on quite a few things.

The client and vendor began to "work together on this" because of the mutually dependent relationship. The vendor was trying to develop a system to sell within the furniture industry. The client needed a system to comply with their manufacturer. The initial problems with the vendor stemmed from their unwillingness to make adjustments to the system that were considered by the client to be "commonsense" to anyone who "knew the business." One major example of the problematic relationship was the "bug list." The people at Furniture Co. gave a huge list of "bugs" that were interfering with the proper running of the system, making it difficult for people to do their work. However, the vendor classified "bugs" as "enhancements," meaning that it would cost Furniture Co. extra for the vendor to address it. If the issue is classified as a bug, then it is covered under the current contract and would not cost extra. The constant battles over "bugs" and "enhancements," "practice" and "process," demonstrates how issues of power and knowledge function in this client/vendor relationship.

The new lead consultant was lauded by the same management for his willingness to work with, learn from, and in many instances advocate for Furniture Co. This transformed what was a shared dependency to a willingness to work together constructively. The client brought with them an in-depth understanding of how their work gets done. The consultant brought with him an understanding of the system, how it works, and how it could be changed. Together, they were able to embark on a design that is a hybrid of industry-wide "best practice" and organizational-wide "local practice." This system was meant to be flexible and adaptable to the local contingencies that had emerged over time in the context of Furniture Co., as demonstrated by the CIO:

\footnotetext{
There was a place where the user interface on that software was simple. It was logi$\mathrm{cal}$, it made sense, it flowed, and the other one was rigid. One was a business process and one was a tool, and the one we selected was a tool, with parameters you could set, however you wanted to use them. The other software just dictated your business, and that was very clear to me up front.
}

This shows her orientation to technology as a tool, rather than technology as a determinant. Already comfortable with their business processes, Furniture Co. saw no reason to dramatically reengineer. A major point of the new system was to allow for increased functionality and a new level of integration of information across the organization. They were not looking for the system to determine how their business would run. On the contrary, they were looking for the system to help them run their organization in the way they wanted, and that was based on how work already got done.

This philosophy extended to how Furniture Co. treated its offices distributed throughout New England. When ES systems are implemented, there is a tendency to make all distributed sites use the same standard system. This approach can prove quite problematic when considering global companies that have sites around the world with very different 
business and workplace practices. The same can be true for a relatively small furniture distribution company:

\begin{abstract}
Interviewer: Was the goal to get their processes to be common or. . ?
CIO: Yes, in common for however it made sense and commonality in the accounting process. Accounting is accounting, and it is a PAR and now we do it the same, but now customer service and selling and business, that is a little different. Our customer service people in Boston don't have [inaudible]. There customer service people there [inaudible]. There are differences. We have a much bigger warehouse, bigger crew, more trucks, and they don't have all their own installers. So the processes had to be a little bit different. We have a Rhode Island office that doesn't have any of their own installers, so the paperwork is different. We send it all out and have to figure out how that will take place.
\end{abstract}

Interviewer: You have to take care of processes. Do you have different processes for New England?

CIO: It is all in one book, but they follow different processes.

This was part of a larger conversation regarding how the system would have to be adapted to the local contingencies of workplace practice. As the CIO indicates, some workplace practices generally are standard, and therefore having a standardized system is not particularly problematic. At the same time, other areas can be different, and there needs to be flexibility in the system.

It is the acknowledgement of the divergences in workplace practice, and the insistence on a system that can respond to these divergences, that led to the relatively successful integration of the system into Furniture Co. The biggest issue was getting the vendor to comply with the wishes of the company. The second biggest problem involved training company personnel on the system. Here again, the original representative from the vendor company was seen to be woefully inadequate. As a result, Furniture Co. took over the training process, developing their own materials and tutorials for how to use the system. Furniture Co. personnel even ran the training program. This level of ownership from management to workers allowed for a broader level of buy-in regarding the use of the system. Of course, this does not mean to say that the integration was seamless and nonproblematic in terms of people getting used to the system. However, it does demonstrate how attention to the contingencies of localized workplace practice in the development of the system can facilitate the integration of the system to support activities of the organization.

\title{
Discussion
}

XYZ consultants embark with their clients on a process of examining "business processes" prior to a system implementation. The level of analysis is restricted to discussions of methodologies, workflows, and narrative accounts of worker responsibilities. These are 
taken to be a representation of how work actually gets done. In doing this they ignore any local perspective of daily work practice; indeed as we have seen, they dismiss these "different work habits" as idiosyncrasies that need to be eradicated. Crabtree (2003) notes that this loss of a local perspective can be the first misstep in the development of systems. Lucy Suchman, in her seminal work Plans and Situated Actions (1987), also pointed out the limitations of trying to develop systems based on theoretical accounts and models of how work is done (or plans) versus a detailed understanding of how technology is actually used as an artifact of the workplace (or situated actions). Formal models of action viewed through a formal analytic and interpretive lens (see Garfinkel, Sacks, 1969) invariably lose the phenomenon itself. Her findings indicate that by keeping the level of analysis at observable behavior and practice, rather than abstract notions of process, systems can be better designed to perform their role.

Scapens $(1984,1994)$ makes a similar observation in his survey of management accounting research. He found that "There was a clear gap between the theoretical material in textbooks, which was intended to show practitioners how management accounting should be done, and the actual practices of management accountants in both U.K. and U.S. companies" (1994: 301-2). Rather than trying to go "by the book," Scapens "encourages researchers to look seriously at the nature of all management accounting practices, and not to dismiss those practices which do not conform to some theoretical ideal" (p. 301). In fact, the actual practices exhibited in the course of daily work should be the basis for developing "rules" of work. In this way, practices inform rules rather than rules (or in the scope of this paper "process") informing practices (Ciborra and associates, 2000). This was indeed what Furniture Co. attempted to do in designing their ES.

These comments about the need to look at practice (rather than process or abstract models) have been aimed at academic researchers. We suggest that the same criticisms and the same need to focus on practice can be aimed at ES consultants. When consultants adopt and endorse an overly cognitivistic and computational model of workplace processes and then distill this view into a technological system, social elements of work are potentially lost. As a result, the launching of a new system meant to improve productivity and work can in fact have the opposite effect. This is because rule-based, or "best practice," derived systems fail due to a "one size fits all" or "vanilla" approach that dictates a common set of procedures across companies with little regard for the actual organizational context (Caraynnis, 1999: 220). Part of this is attributable to the disruption in the communities of practices as they are expected to reorganize (or reengineer) their activities to the new technology and to accountability structures that allow for less flexibility. Furthermore, information and meaning can be lost, as can the social context from which the changes are derived. Brown and Duguid (2002: xvi) refer to the belief that "information and its technologies can unproblematically replace the nuance relations between people" as information fetishism. We can by extension refer to the belief that people need to be organized around technology (and not vice versa) as technological fetishism.

The belief that rules guide workplace practice will lead to the belief that technical systems built around rules can replace and reengineer workplace practice. On the other 
hand, the belief that social relations, norms, and communities of practice are at the center of workplace practice will lead to the belief that systems must be built to support these social and cultural elements of the workplace. Speaking to this point, Suchman (2000) states, "Our efforts to develop a work-oriented design practice were in the recognition that systems development is not the creation of discrete, intrinsically meaningful objects, but the cultural production of new forms of material practice." Similarly, Ciborra (2000: 31) notes: "The intricacies and uncertainties of ambiguity, hospitality, and hostility are ruled out from such a world of abstract organizations, ["the world of business process reengineering models, where designers, consultants, and managers juggle around boxes and arrows to come up with solutions that optimize pre-selected performance criteria"], but equally ruled out is the "organizingness" of everyday business life (that is, the essence of the experience of operating in an organization)". Rather than seeing information and enterprise systems as separate from workers and the ways in which they work, an alternative view is to see technology as embedded in workplace practice. In order to develop a system to support innovation, productivity, and work, systems need to be built with attention to the social aspects of everyday workplace activity. Ciborra and associates (2000), recognizing the social embededness of practice, introduce the concepts of care, hospitality and cultivation as essential ingredients for successful information system implementations, each recognizing the inherently social or "organizingness" of work practice.

To take into account the "organizingness" of work practice, demands a different approach to ES design and implementation; an approach based on ethnomethodology, rather than an approach that starts with a blank sheet and identifies idealized processes. Ethnomethodology literally translates into "the study of member's methods," and means that social order is comprised of the coordinated activities of persons engaged in any setting. The job of the consultant adopting this approach would be to focus on the practices exhibited by persons as the basis for social order. Or, according to Sharrock and Hughes (2001: 6), "ethnomethodology refuses any epistemological or ontological commitments, and limits its enquiry rigorously to what is directly observable and what can be plausibly inferred from observation on a known-in-common basis." This means that theoretical constructs or methodological and demographic categories are eschewed for direct observation of the phenomenon itself that is under study.

This is precisely the approach adopted by workplace studies scholars and practitioners. Schmidt (2000: 149) states the importance of workplace studies is "to dismantle prevalent common-sense notions of cooperative work by uncovering how orderly cooperative work is routinely and inconspicuously accomplished." Thus, common-sense is typically taken-for-granted, and as a result eludes workers' own understandings. This results in the need for a purposeful examination of specific details of workplace activity. Heath and Luff (2000: 19), for example, explain how ethnomethodology has impacted research on technology in the workplace: 
[I]n contrast to related research, workplace studies informed by ethnomethodology and conversation analysis are not principally concerned with "meaning" or "representation," whether individual or shared; they are not concerned with cognition or learning (at least in its cognitive sense); and they do not focus on the ways in which situations shape human experience and activities. Rather, the recent array of ethnomethodological studies of work and technology ... directs analytic attention towards the socially organized practices and reasoning in and through which participants produce, recognize and co-ordinate their (technologically informed) activities in the workplace.

Were consultants to adopt this approach, their focus would shift from process to practice, or from a model of how work should be done to observances of how work is actually done. By suspending assumptions and theoretical frameworks regarding what is happening, the consultant is able to get a more accurate read on the organization of people and artifacts in the workplace setting. The basis of design becomes what people do, and the technological systems are positioned to enable this activity. The consultant in Furniture Co. did move in this direction, taking the lead from the senior management team who had originally done a very detailed analysis of work practices, and so came to understand why the ES that his company was trying to push onto Furniture Co. was not appropriate. In this instance, Furniture Co. had more power over their consultant than is typical because they were jointly working on developing the ES as a "best practice" industry model. The consultants in XYZ who dismissed local practices as "different work habits" is likely to be more common and, we argue, more potentially disruptive.

We are thus advocating a new consultancy approach of "everyday ethnography," an approach based on understanding work practice rather than providing idealized accounts of business processes. A process-based approach often incorporates a best practices model where an idealized version of the workplace takes precedent over the actual behaviors currently in place. This, coupled with a business reengineering approach, can result in major disruptions to the workplace as well as being counterproductive to supporting actual work practice.

\section{Conclusion}

A primary concern when designing and implementing technological systems (such as ES) is the extent to which the system helps to increase productivity. ES seek to achieve this goal by facilitating knowledge transfer and making information available to the relevant sectors of the organization. This integrative capacity is seen as the critical component that makes ES more desirable when compared to legacy systems. By making knowledge and information more accessible, the theory is that people will be in a better position to make more informed decisions in a timely manner, making an organization making full use of the ES more competitive.

At the same time, ES alone are not necessarily enough to deliver this payoff. Many consultants and industry experts assert that companies need to "reengineer" their work- 
place to realize the full benefits of technology. Information systems (including ES) are typically predicated on some set of rules or conceptualizations of how work is done and/ or should be done. However, rules can be disruptive to actually getting work done. As Luff, Hindmarsh and Heath (2000: 7) note, "Despite the good intentions of designers in making work activities more visible and manipulatable by those who undertake them, the technology might actually undermine their accomplishment." In fact, workers frequently employ a technique called "work to rule" where they slow down the pace of work by following the rules of the workplace. In other words, doing no more than the minimum, as explicitly stated in one's contract or other descriptions of occupational expectations, causes less work to be done. As Hammer and Champy note (2003: 18), "Programming people to conform to established procedures remains the essence of bureaucracy even now. The command-and-control systems in place in most companies today embody the same principles the railroads introduced 150 years ago." These command-and-control systems emphasize the conformity of people to the technical systems that they use, rather than the other way around.

Our findings indicate that a significant part of the problem lies in consultants' focus on process over practice, and radical technologically-based reengineering versus more endogenously-based incremental change. Furthermore, we propose that technology needs to be seen more as an enhancement to workplace practice rather than as a way to construct business processes. When technology is used to structure the workplace irrespective of actual practices, it can be extremely disruptive to the "communities of practice" that are essential to knowledge development and sharing. These communities are not predicated upon any standardized set of rule or laws that dictate precisely how members need to act. This is not to say that rules, manuals, or standardized sets of procedures do not exist, or do not help to establish the broad parameters or outlines for action. However, as with societies, laws do not establish everyday activity. For instance, a new immigrant does not learn how to "act American" by going to law school and learning legal codes. While this explicit knowledge might be helpful in certain respects, it would not inform the person about how to dress, walk down the street, carry on a conversation, stand in a queue, or assemble in a public place.

Consultants and clients need to emphasis the study of workplace practices as the first step in any system design. Even "quick and dirty ethnographies" (Hughes, Randall, Shapiro, 1993: 4-5) could be effective in helping to move the consultant (and the manager) from the ideal-type process model to a more realistic account of workplace practice. In doing so, a system can be developed that can support productivity rather than disrupt it. Change is inevitable with the introduction of any new technology. This change is more likely to be successful if it is incremental, embedded, and symbiotic in the sense that it emerges from the workplace setting itself. This can require a more long-term strategy to organizational change, rather than trying to achieve a rapid shift through technological implementation. This conservative approach, however, can be less disruptive in the short-term, leading to less loss in productivity while the new changes emerge. Along with consultants, senior managers need to be more willing to allow change to emerge, which 
requires giving up a certain amount of control. At the same time, this can be empowering to workers who play a more fundamental role in the implementation process as it is their activities that are the basis for design. Through this practice-based approach to system design, consultants and clients stand a better chance of success in the short-term and stable change in the long-term.

\section{References}

Alvesson M. (2001) Knowledge Work: Ambiguity, Image and Identity. Human Relations, vol. 53, no 1, pp. 7-32.

Barley S. R. (1996) Foreword. J. E. Orr, Talking about Machines: An Ethnography of a Modern Job, Ithaca, NY: Cornell University Press, pp. ix-xiv.

Bloomfield B. P., Best A. (1992) Management Consultants: Development, Power, and the Translation of Problems. Sociological Review, vol. 40, no 3, pp. 533-56o.

Callon M. (1986) Some Elements of a Sociology of Translation. Power, Action and Belief (ed. J. Law), London: R.K.P., pp. 196-233.

Ciborra C. (1996) Introduction: What Does Groupware Mean for the Organizations Hosting It? Groupware and Teamwork: Invisible Aid or Technical Hindrance? (ed. C. Ciborra), Chichester: Wiley, pp. 1-19.

Ciborra C. and associates (2000) From Control to Drift: The Dynamics of Corporate Information Infrastructures, Oxford: Oxford University Press.

Clark T., Salaman G. (1998) Creating the "Right" Impression: Towards a Dramaturgy of Management Consultancy. Service Industries Journal, vol. 18, no 1, pp. 18-38.

Colclough G., Tolbert II C. M. (1992) Work in the Fast Lane: Flexibility, Divisions of Labor, and Inequality in High-Tech Industries, Albany, NY: SUNY Press.

Crabtree A. (2001) Doing Workplace Studies: Praxiological Accounts - Lebenswelt Pairs. TeamEthno Online, no 1. Available at: http://archive.cs.st-andrews.ac.uk/STSEHandbook/Other/Team\%2oEthno/Issue1/Crabtree/Crabtree.html (accessed 20 December 2015).

Crabtree A. (2003) Designing Collaborative Systems: A Practical Guide to Ethnography, London: Springer.

Dant T., Francis D. (1998) Planning in Organisations: Rational Control or Contingent Activity? Sociological Research Online, vol. 3, no 2. Available at: http://www.socresonline.org.uk/3/2/4.html (accessed 20 December 2015).

Garfinkel H., Sacks H. (1969) On Formal Structures of Practical Actions. Theoretical Sociology: Perspectives and Developments (eds. J. C. McKinney, E. Tiryakian), New York: Appleton-Century-Crofts, pp. 337-366.

Goffman E. (1959) The Presentation of Self in Everyday Life, New York: Doubleday.

Haines M. N., Goodhue D. L. (2003) Implementation Partner Involvement and Knowledge Transfer in the Context of ES Implementation. International Journal of HumanComputer Interaction, vol. 16, no 1, pp. 23-38. 
Hammer M., Champy J. (2003) Reengineering the Corporation: A Manifesto for Business Revolution, New York: HarperBusiness Essentials.

Heath Ch., Luff P. (2000) Technology in Action, Cambridge, UK: Cambridge University Press.

Hughes J. A., Randall D., Shapiro D. (1993) From Ethnographic Record to System Design. Computer Supported Cooperative Work, vol. 1, no 3, pp. 123-141.

Jones M. (2003) The Expert System: Constructing Expertise in an IT/Management Consultancy. Information and Organization, vol. 13, no 4, pp. 257-284.

Koskinen I. (2000a) Plans, Evaluation, and Accountability at the Workplace. Sociological Research Online, vol. 4, no 4. Available at: http://www.socresonline.org.uk/4/4/koskinen.html (accessed 20 December 2015).

Koskinen I. (20oob) Workplace Studies: An Ethnomethodological Approach to CSCW. Paper presented at the Nordic Interactive meeting. Helsinki, Finland. March 31.

Latour B. (1987) Science in Action: How to Follow Scientists and Engineers Through Society, Cambridge, MA: Harvard University Press.

Luff P., Hindmarsh J., Heath Ch. (2000) Introduction. Workplace Studies: Recovering Workplace Practice and Informing System Design (eds. P. Luff, J. Hindmarsh, Ch. Heath), Cambridge, UK: Cambridge University Press, pp. 1-26.

Lynch M. (2002) Protocols, Practices, and the Reproduction of Technique in Molecular Biology. British Journal of Sociology, vol. 53, no 2, pp. 203-220.

Michel R. (1998) IT Services Take Center Stage. Manufacturing Systems.

Orlikowski W. (1991) Integrated Information Infrastructure or Matrix of Control? The Contradictory Implications of Information Technology. Accounting, Management and Information Technology, vol. 1, no 1, pp. 9-41.

Orlikowski W. (1996) Improvising Organizational Transformation over Time: A Situated Change Perspective. Information Systems Research, vol. 7, no 1, pp. 63-91.

Schmidt K. (2000) The Critical Role of Workplace Studies in CSCW. Workplace Studies: Recovering Workplace Practice and Informing System Design (eds. P. Luff, J. Hindmarsh, Ch. Heath), Cambridge, UK: Cambridge University Press, pp. 141-149.

Sharrock W. W., Anderson B. (1986) The Ethnomethodologists, New York: Tavistock Publications.

Sharrock W. W., Hughes J. A. (2001) Ethnography in the Workplace: Remarks on Its Theoretical Bases. TeamEthno Online, no 1. Available at: http://lib.babr.ru/ext/4567. pdf (accessed 20 December 2015).

Suchman L. A. (1987). Plans and Situated Actions: The Problem of Human-Machine Communication, Cambridge, UK: Cambridge University Press.

Suchman L. A. (2000) Located Accountabilities in Technology Production. Available at: http://www.lancaster.ac.uk/fass/resources/sociology-online-papers/papers/suchmanlocated-accountabilities.pdf (accessed 20 December 2015).

Suchmah L. A., Trigg R., Blomberg J. (2002) Working Artifacts: Ethnomethods of the Prototype. British Journal of Sociology, vol. 53, no 2, pp. 163-179.

Walsham J. (1993) Interpreting Information Systems in Organizations, Chichester: Wiley. 


\section{Практики, процессы и системное проектирование: почему консультанты должны быть «этнографами повседневности»}

\section{Гэри Дэвид}

Профессор социологии департамента социологии Университета Бентли

Адрес: 175 Forest str., Waltham, Massachusetts, USA 02452

E-mail: gdavid@bentley.edu

\section{Сьюзан Ньюэлл}

Профессор информатики департамента бизнеса и менеджмента Университета Сассекса

Адрес: Sussex House, Falmer Brighton, United Kingdom BN1 9RH

E-mail: sue.newell@sussex.ac.uk

Корпоративные системы (КС) призваны соединять между собой различные функции организации путем интеграции информационных потоков, управления данными, организационных процессов и действий на рабочих местах. По сравнению с унаследованными системами, которые могут «оседать» в разрозненных частях организации, корпоративные системы должны использоваться на всем «предприятии». Важнейшие преимущества этих систем состоят в большей стандартизации труда и управления данными, а также в обеспечении принятия лучших решений и более быстрой реакции на меняющиеся условия. Вызывая фундаментальный сдвиг в способе осуществления работы, КС могут, по сути, оказывать разрушительное воздействие, по мере того как технологический ландшафт организации трансформируется вследствие внедрения новой информационной системы. Это также способствует их неудаче, поскольку установка системы часто сопровождается большими задержками, сопротивлением пользователей и неспособностью интеграции с существующей рабочей практикой. В настоящей статье мы противопоставляем реинжиниринговые подходы (т.е. реструктурирование работы) внедрениям, в которых технологии более приспособлены к существующим рабочим практикам, что позволяет осуществлять более плавные и менее разрушительных изменения. Мы полагаем, что, хотя консультанты упорно настаивают на внедрении КС, в основе которых лежит реинжиниринг, принимаемая ими методология понимания существующих бизнес-процессов такова, что они способны составить только идеализированный образ этих процессов, часто очень отличающийся от действительной практики в специфическом контексте. Вместо этого мы предлагаем консультантам использовать более практикоориентированный, этнометодологический подход, т.е. фактически стать этнографами повседневности, которые помогают принимать более взвешенные бизнес-, организационные и административные решения.

Ключевые слова: информационные системы, исследования рабочих мест, этнометодология, корпоративные системы, реинжиниринг, консультанты, бизнес-процессы 